\title{
Plano de ação para a Área de Proteção Ambiental de Barra do Piraí/RJ
}

\section{Action Plan for Environmental Protection Area in Barra do Piraí / RJ}

\author{
1 Francisco Jácome Gurgel Júnior gurgel.j@@gmail.com \\ 2 Mariana Avila Corrêa Cardoso de Oliveira
}

\footnotetext{
1 Doutor em Ciências Ambientais e Florestais, Docente do curso de Engenharia Ambiental e Engenharia Civil do UniFOA e da Secretaria Estadual de Educação do Rio de Janeiro (SEEDUC/RJ).

2 Discente da Engenharia Ambiental - UniFOA.
}

\section{RESUMO}

O mundo aparenta estar cada vez menor, mais restrito, com todos os seus espaços explorados e expostos à curiosidade e à ação humana. $\mathrm{A}$ visitação em áreas protegidas e, em especial, nas unidades de conservação, vem acarretando a degradação do meio ambiente em todas as suas manifestações pela ausência de Planos de Manejo, pela inexistência e/ou ineficiência da fiscalização ambiental e, principalmente, pelo desconhecimento dos visitantes e da comunidade residente no entorno dela. Muitas são as iniciativas de se buscar a preservação e o manejo ambiental de unidades de conservação, considerando-se sua importância, seus recursos ambientais associados e os serviços ambientais que presta. Partindo dessa premissa, é que se torna imprescindível e exequível a elaboração de projetos que contemplem o planejamento, o gerenciamento e o monitoramento de áreas protegidas, para que se alcance a compatibilização da visitação com a proteção da área em toda a sua integralidade. 0 cenário escolhido para a realização deste estudo é a Área de Proteção Ambiental do município de Barra do Piraí, localizada à Rua Antônio Félix Pinheiro, $n^{\circ} 1025$, bairro Represa. A partir do histórico, sua criação, pesquisa e evolução da atual área protegida, foram detectadas algumas fragilidades e potencialidades que nortearam este estudo e que subsidiaram as propostas descritas e consubstanciadas pelos projetos apresentados, que poderão ser implementadas com o objetivo de humanização, educação ambiental de caráter formal e não formal, recuperação e otimização do espaço de suma importância para os barrenses.

\section{Palavras-chave:}

Plano de ação. Área de proteção ambiental. Unidade de conservação. Barra do Piraí/RJ.

\begin{abstract}
The world appears to be smaller, more restricted, with all its spaces explored and exposed to human curiosity and action. Visitation in protected areas and especially in conservation units has led to environmental degradation in all its manifestations because of the absence of Management Plans due to the lack of and / or inefficiency of environmental inspection and mainly due to the lack of knowledge of visitors and the community residents in its vicinity. There are many initiatives to seek the preservation and environmental management of conservation units, considering their importance, their associated environmental resources and the environmental services it provides. Based on this premise, it is essential to prepare projects that contemplate the planning, management and monitoring of protected areas in order to achieve the compatibility of the visitation with the protection of it in its entirety. The scenario chosen for this study is the Environmental Protection Area of the municipality of Barra do Piraí located at Rua Antônio Félix Pinheiro, n01025, Represa district. Based on the history, creation, research and evolution of the current protected area, we detected some weaknesses and potentialities that guided this study and that subsidized the proposals described and embodied by the projects presented and that could be implemented with the objective of humanization, environmental education aspects of formal and nonformal character, recovery and optimization of that space of great importance for the people from Barra do Piraí.
\end{abstract}

\section{Keywords:}

Action Plan. Environmental Protection Area. Conservation Unit. Barra do Piraí/RJ.

\section{Como você deve citar?}

GURGEL JÚNIOR, Francisco Jácome; OLIVEIRA, Mariana Avila Corrêa Cardoso de. Plano de ação para a Área de Proteção Ambiental de Barra do Piraí/RJ. Cadernos UniFOA, Volta Redonda, n. 38, p. 129-137, dez. 2018. 


\section{INTRODUÇÃO}

A Mata Atlântica, patrimônio nacional (Artigo 225, da Constituição Federal de 1988), encontra-se em processo de extinção pelo desmatamento desenfreado, pelas queimadas, pela ocupação desordenada, pela caça ilegal e por demais ações antrópicas que estão reduzindo drasticamente sua área. Logo em seguida ao descobrimento, grande parte da vegetação da Mata Atlântica foi destruída devido à exploração intensiva e desordenada da floresta. A história geológica da área primitivamente ocupada pela Mata Atlântica é rica em episódios distintos, de variada natureza que, no passado, significaram profundas modificações ambientais. Com poucas exceções, as unidades de conservação possuem áreas insuficientes para uma preservação natural de sua biota, especialmente no que tange à fauna, sendo necessários monitoramento e manejo constantes, além de restauração dos habitats já degradados, procedimentos que, na realidade, não estão sendo praticados, salvo em pouquíssimos casos especiais (CÂMARA, 1996). Seguindo esses procedimentos, a Área de Proteção Ambiental de Barra de Piraí potencializaria suas funções ecológicas, pois, apesar de fragilizada, desempenha um grande papel ambiental, com extensão de 130 hectares, sendo que apenas dois hectares ainda apresentam vegetação nativa, dividida em 6 (seis) fragmentos distintos. Faz divisa com os Municípios de Mendes e Piraí e integra o Corredor de Biodiversidade de Mata Atlântica denominado Tinguá-Bocaina, localizado nas seguintes coordenadas geográficas $43^{\circ} 48^{\prime} 43.74^{\prime \prime}$ O. e $22^{\circ} 22^{\prime} 00.00 " S$ (OLIVEIRA, 2006), conforme se observa na figura 01.

Figura 01 - Área presumida da APA de Barra do Piraí.

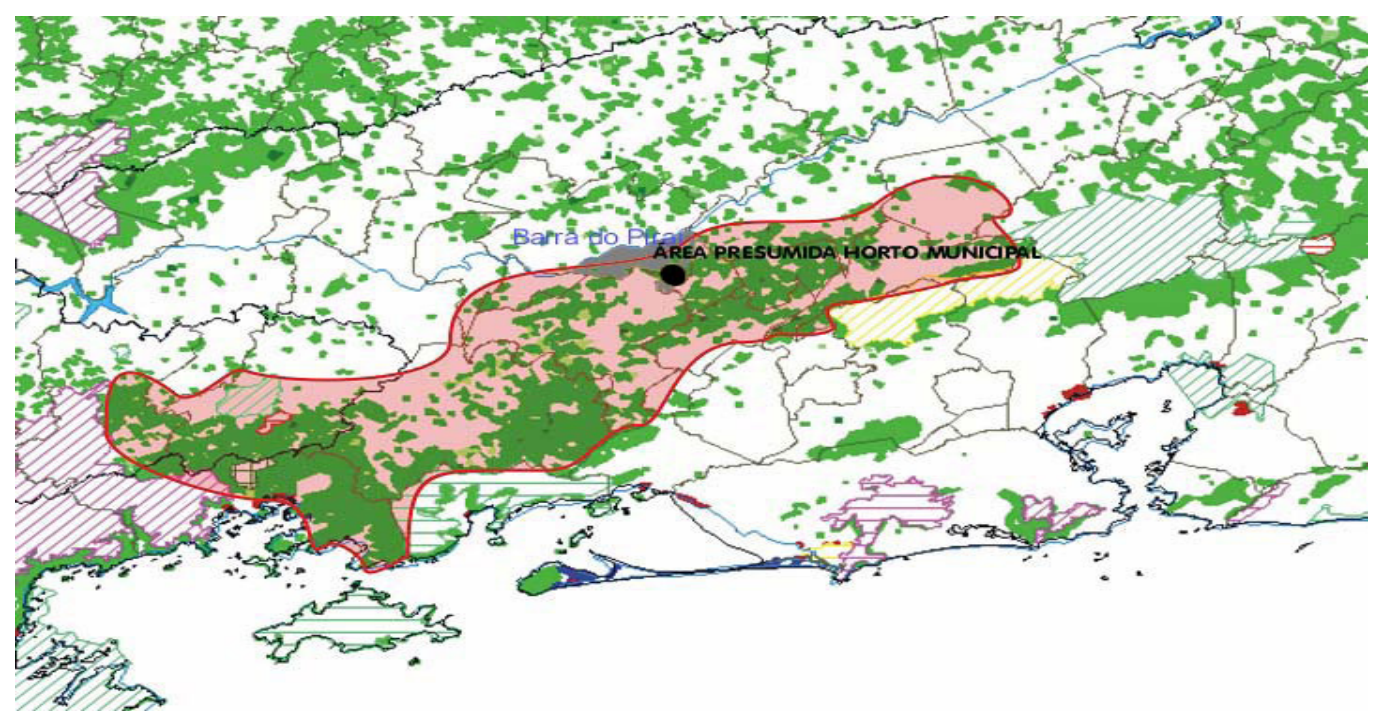

Fonte: Secretaria Municipal de Meio Ambiente de Barra do Piraí.

O principal serviço ambiental que a APA presta atualmente é o abastecimento de água para a Estação de Tratamento de Água do Horto (ETA - 4), localizada próximo à entrada, produzindo $40 \mathrm{~m}^{3}$ de água potável para cerca de 500 domicílios dos bairros Química, Novo México, Caixa D Água Velha, parte do bairro Caieira de São Pedro e ruas próximas do Centro da cidade, totalizando cerca de 2.500 habitantes localizados no entorno da APA (OLIVEIRA, 2006). De acordo com Silva (2007) e Franca (2006), um plano de ação voltado para a gestão de uma unidade de conservação cumpre o papel de orientar seus gestores e o seu respectivo conselho consultivo a discutir os assuntos da unidade e decidir coletivamente as ações que melhor cumpram sua missão de proteção, recuperação ambiental e interação com as áreas e comunidades de seu entorno. Os Conselhos Gestores de Unidades de Conservação são o palco para a construção do consenso e para a gestão dos conflitos envolvendo a conservação, a proteção e o uso dos recursos naturais de uma Unidade de Conservação e de sua circunvizinhança. 
Esta pesquisa tem enfoque socioambiental e de conservação das diversidades biológica e cultural, na exploração de trilhas perceptivas e interpretativas e se caracteriza como um experimento educacional de caráter transdisciplinar que integra objetivos educacionais, conservacionistas e terapêuticos. Em unidades de conservação ambiental devem ser tomadas medidas para prevenir e minimizar o aparecimento de pragas, doenças, ocorrências de incêndio e a introdução de plantas invasoras (FAILLACE, 2001). Coelho, Cunha e Monteiro (2009) endossam que as unidades de conservação quase sempre são vistas como objetos naturais, e não como objetos criados (concebidos, inventados, disputados), que devem ser objeto de investigação em construção e necessitam da harmonia entre os grupos sociais (tradicionais ou não) e os recursos, bem como os processos de mudanças sociais, ambientais e territoriais. A recuperação dos mananciais se dá num processo gradativo de recolonização vegetal das nascentes (ASSIS, 2001). Em razão disso, no Brasil, a exemplo de muitos outros países, são criadas diversas unidades de conservação, visando-se além da proteção dos recursos bióticos, a conservação dos recursos físicos e culturais desses mesmos espaços naturais (CHAVES, 2006). Antunes (2011) frisa que destinar uma área para a proteção especial - qualquer que seja o motivo- é, do ponto de vista jurídico, dotá-la de um regime especial que não se confunde com o regime de livre acesso para toda e qualquer atividade ou pessoa. Santilli (2005) enumera como espaços territorialmente protegidos as categorias de unidades de conservação elencadas na lei do SNUC, as áreas de preservação permanente, a reserva legal, os biomas constitucionalmente protegidos (a floresta Amazônica, a Mata Atlântica, a serra do Mar, o Pantanal Matogrossense e a Zona Costeira, previstos no artigo 225, parágrafo $4^{\circ} \mathrm{da}$ Constituição Federal de 1988), as cavernas, os sítios arqueológicos, os bens culturais tombados, os hortos florestais, jardins botânicos e zoológicos e as reservas da biosfera. 0 conjunto de Programas, ao que se espera, deverá atender às principais necessidades de conservação de toda a área da Mata Atlântica, atuais e futuras (CÂMARA, 1996). Com atuações em sua revitalização e otimização, permitirá um estudo de caso, minimizando as fragilidades e fortalecendo as potencialidades, visando ao equilíbrio do ambiente.

O objetivo deste trabalho é a compreensão do processo de formação da unidade de conservação, suas fitofisionomias predominantes, a comunidade visitante e aquela residente na circunvizinhança, para que, assim, se possa produzir um diagnóstico detalhado da área em tela.

\section{MATERIAIS E MÉTODOS}

Barra do Piraí é um município brasileiro, pertencente ao estado do Rio de Janeiro. Localiza-se a uma latitude $22^{\circ} 28^{\prime} 12^{\prime \prime}$ sul e a uma longitude $43^{\circ} 49^{\prime} 32^{\prime \prime}$ oeste, estando a uma altitude de 363 metros. Sua população, segundo o Censo de 2010, é de 94.855 habitantes. Possui uma área de $582,1 \mathrm{~km}^{2}$ e se localiza no centro da Região Sul Fluminense, onde faz fronteira com os municípios de Valença, Vassouras, Mendes, Piraí, Pinheiral, Barra Mansa e Volta Redonda (Portal da PMBP, 2018).

Segundo o artigo $2^{\circ}$, I, da Lei Federal n 9.985/00 (Lei do S.N.U.C.), unidade de conservação é o "espaço territorial e seus recursos ambientais, incluindo as águas jurisdicionais, com características naturais relevantes, legalmente instituído pelo Poder Público, com objetivos de conservação e limites definidos, sob regime especial de administração, ao qual se aplicam garantias adequadas de proteção". Conforme o Cadastro Nacional de Unidades de Conservação (CNUC), produzido pelo Ministério do Meio Ambiente (MMA) e atualizado em 01/02/2018, existem trezentas e dezenove áreas de proteção ambiental no Brasil, sendo 33 federais, 190 pertencentes aos estados da federação e 96 em municípios. Para a realização do estudo de caso, o cenário é a Área de Proteção Ambiental (APA) de Barra do Piraí, onde a metodologia empregada consistiu na pesquisa de documentos produzidos sobre a unidade, como artigos científicos, relatórios técnicos, dissertações de mestrado, teses de doutorado e outros acerca da área protegida; entrevista com moradores das imediações; análise criteriosa do local com o 
devido registro fotográfico; visualização de mapas sobre a unidade de conservação; identificação das fragilidades e dos potenciais, por meio de visitas; busca de informações com os funcionários do outrora Horto Florestal; caracterização e conhecimento do processo participativo da comunidade que vive em seu entorno e usufrui dos serviços ambientais e; apoio institucional da Secretaria de Meio Ambiente, que autorizou a pesquisa. Com a obtenção das informações da unidade de conservação, será possível a produção de Plano de Ação pormenorizado que esteja em consonância com os objetivos gerais dessa categoria de área protegida, que é de uso sustentável, dotada de atributos abióticos, bióticos, estéticos ou culturais importantes para a qualidade de vida e o bem-estar das populações humanas, visando basicamente à proteção da diversidade biológica, à disciplina do processo de ocupação e à sustentabilidade do uso dos recursos naturais (SNUC, 2000).

\section{RESULTADOS E DISCUSSÃO}

\subsection{Projetos de Gestão Compartilhada}

\subsubsection{Projeto "Participando do Conselho Gestor"}

O objetivo do projeto de Gestão Compartilhada é o incentivo à comunidade residente no entorno, comunidade científica e Poder Público em todas as suas esferas para a efetiva participação no Conselho Gestor da APA Municipal de Barra do Piraí, para atendimento ao disposto no Decreto Municipal $n^{\circ} 30 / 2008$, possibilitando a gestão descentralizada e participativa. 0 processo de gestão deverá se iniciar com uma primeira reunião do Conselho Gestor, realizando as seguintes atividades: convocação das entidades interessadas para eleição do conselho gestor; eleição aberta para os membros do conselho gestor; capacitação dos conselheiros eleitos e atuação do conselho gestor no apoio ao Gestor da área protegida e posterior feitura do Plano de Manejo. As atividades deverão ser realizadas em curto prazo, avaliadas bimensalmente e serão de responsabilidade da Secretaria Municipal de Meio Ambiente do município de Barra do Piraí. Nesse ínterim, destaca-se a importância da elaboração do Plano de Manejo para a UC, que é o documento técnico, o qual, fundamentado nos objetivos gerais de uma unidade de conservação, se estabelece o seu zoneamento e as normas que devem presidir o uso da área e o manejo dos recursos naturais, inclusive a implantação das estruturas físicas necessárias à gestão da unidade, conforme disposto no artigo $2^{\circ}, \mathrm{XVII}$, da Lei do Sistema Nacional de Unidades de Conservação (2000). É de relevante interesse informar que a APA Barra do Piraí foi criada em 01 de dezembro de 2006, pela Lei Municipal $n^{\circ} 1.190$, que transforma o Parque Florestal Municipal em área de proteção ambiental e que, até a presente data, a Prefeitura de Barra de Piraí ainda não tomou as devidas providências cabíveis, no sentido de atender o dispositivo legal que recomenda a elaboração do Plano de Manejo da área até cinco anos após a data de sua criação.

\subsubsection{Projeto "Aproximando o Homem à Natureza"}

O objetivo deste projeto é a implantação da Sede Administrativa da APA, uma vez que a atual sede encontra-se deficiente para sua gestão, devido a sua precariedade, conforme se observa na figura 02. 0 projeto da nova sede constará de instalações adequadas para a administração e acomodação do gestor designado para a função e sua equipe de apoio, centro de convivência e sala com recursos audiovisuais que será de fundamental importância para a realização das atividades de educação ambiental, eventos culturais e de cidadania, através de dinâmicas, palestras, jogos e gincanas que acontecerão no interior da APA. A obra poderá ser realizada com o auxílio de parceiros e órgãos financiadores, acompanhada e monitorada pelo Gestor da APA a ser designado pela Secretaria Municipal do Ambiente de Barra do Piraí. Uma sede administrativa é de fundamental importância para se controlar o acesso de visitantes, 
orientação deles, bem como para abrigar todos os utensílios e materiais necessários a equipe de fiscais, guarda-parques e brigadistas que exercerão suas atividades na APA Barra do Piraí.

Figura 02- Vista parcial da Sede da APA Barra do Piraí

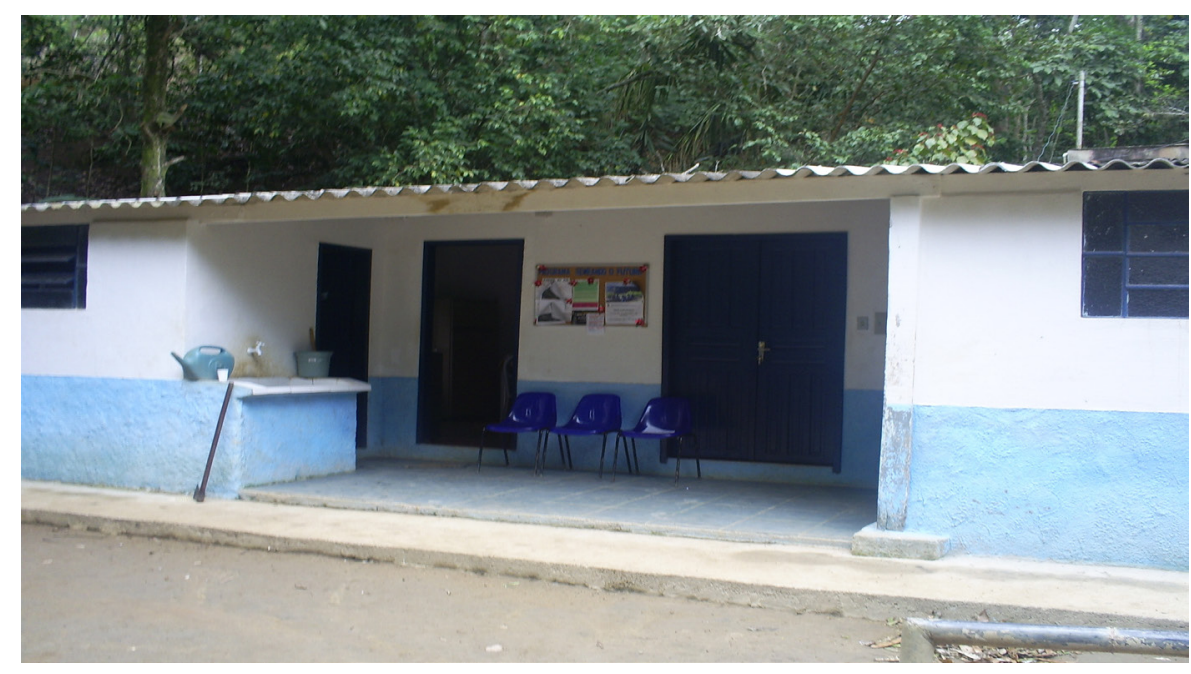

Fonte: Secretaria Municipal do Ambiente de Barra do Piraí.

\subsection{3 "Projeto Conhecendo a APA"}

O projeto visa à viabilização de convênio com universidades públicas e particulares próximas e entidades diversas que queiram participar voluntariamente da gestão compartilhada da APA e desenvolver projetos de pesquisa em seu território, tendo em vista que as universidades são instituições de ensino que detêm o conhecimento e mão de obra qualificada que necessita pôr em prática os conhecimentos adquiridos. Em contrapartida, a APA se mostra como um local ainda desconhecido e que depende diretamente desses estudos científicos para levantamento de sua fauna, flora, solos, potencial hídrico e demais recursos naturais que serão indispensáveis para subsidiar a execução do Plano de Manejo e o monitoramento ambiental da área em tela. A parceria do Poder Público com as instituições de ensino através de convênios poderá instrumentalizar e propiciar a realização dos levantamentos faunístico e florístico, implantação do Centro Conservacionista, reintrodução de pássaros silvestres; implantação de trilhas para educação e interpretação ambiental e ecoturismo; otimização dos viveiros existentes para produção em larga escala e doação de mudas, incentivo aos projetos municipais; produção de adubo orgânico; restauração e/ou recuperação de áreas degradadas identificadas na unidade, reflorestamento e proteção do entorno de suas 15 nascentes, conforme demonstrado na figura 03. Nesse projeto, será também incentivada as visitas de barrenses à unidade por agendamento de horários para Escolas Municipais e Estaduais do município e demais interessados com o intuito de fomentar a educação ambiental (EA) de caráter formal e não formal. A Política Nacional de Educação Ambiental (lei federal $n^{\circ} 9.795 / 99$ ) define a educação ambiental como fruto dos processos, por meio dos quais o indivíduo e a coletividade constroem valores sociais, conhecimentos, habilidades, atitudes e competências voltadas para a conservação do meio ambiente, bem de uso comum do povo, essencial à sadia qualidade de vida e sua sustentabilidade. 
Figura 03- Nascente do Matão

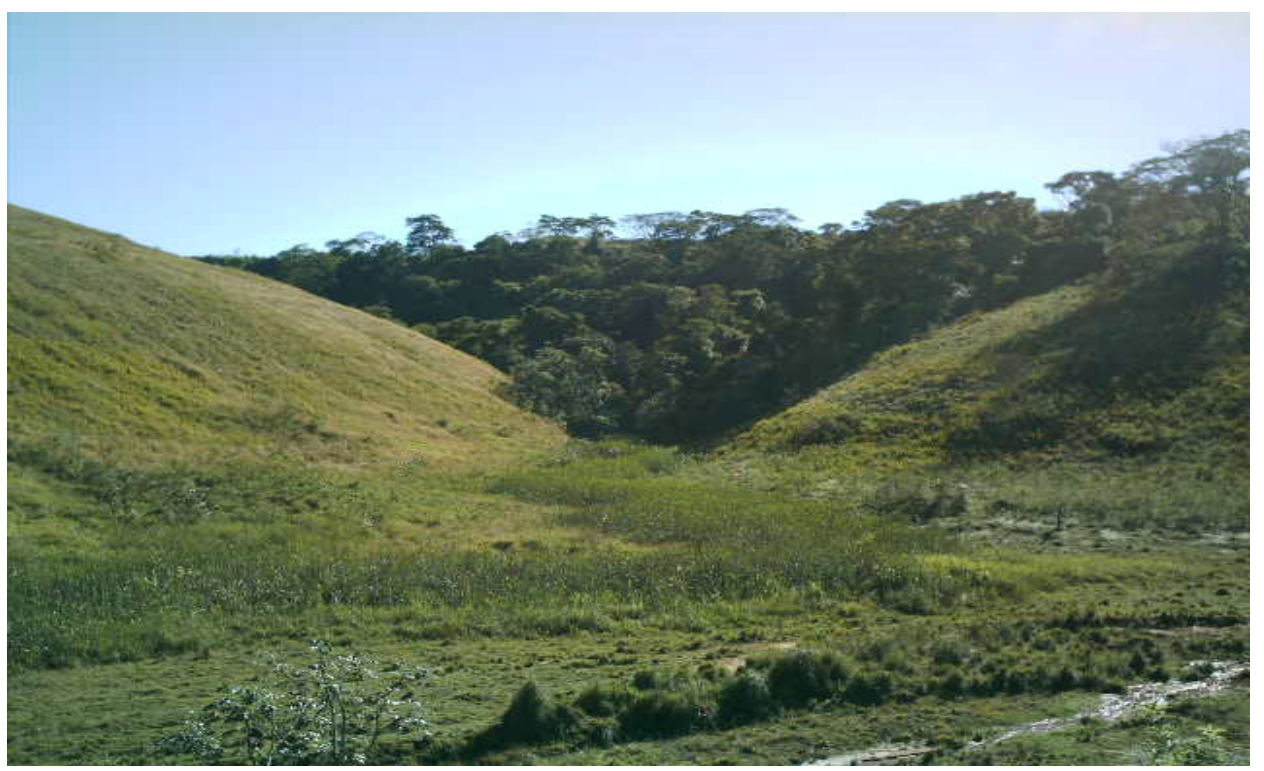

Fonte: Departamento de Recursos Mineras/DRM (Relatório Técnico da APA municipal de Barra do Piraí - Julho, 2007).

O desenvolvimento das atividades previstas no projeto deverão ter sempre o acompanhamento e a aquiescência do Gestor da APA, Conselho Gestor da APA e por profissionais especializados para cada tipo de intervenção e avaliação mensal, nas reuniões ordinárias a serem realizadas pelo Conselho da unidade. Nesse subprojeto sugerido, também se recomenda o apoio técnico das instituições de ensino, para que prestem o devido assessoramento ao Gestor da Unidade, no sentido de providenciar a colocação de sinalização adequada para orientação aos visitantes e pesquisadores que, porventura, percorram as trilhas da área.

\subsection{4 "Projeto de olho na APA"}

O projeto visa à implantação de um corpo de fiscalização ambiental e guarda-parques devidamente treinados e subordinados à Secretaria Municipal de Meio Ambiente do município para atuação na APA. A Fiscalização Ambiental e os guarda-parques são imprescindíveis para se controlar e coibir atitudes que possam ensejar a prática de crimes ambientais no interior e arredores da UC e será formada a partir de concurso público a ser promovido pelo Poder Público Municipal, para dotar a referida unidade de conservação de recursos humanos capazes de executar a devida vigilância e gestão. Deverá também ser estruturado um corpo de brigadistas para combate a possíveis incêndios florestais, composto de voluntários das comunidades do entorno, que receberão treinamento de profissional capacitado e habilitado para tal. A constituição de uma equipe multidisciplinar composta por biólogo, geógrafo, engenheiro florestal e/ou ambiental e geólogo é desejável, pois aumenta a capacidade em executar com precisão o processo de planejamento, gestão e monitoramento de uma unidade de conservação.

\subsection{5 "Projeto Monitorando a APA"}

O objetivo do projeto é a formação de um grupo de alta capacitação técnica e de caráter voluntário que, juntamente com o Conselho da unidade e da equipe de funcionários da APA, possa estar apto a realizar o monitoramento ambiental sistemático da unidade de conservação, com o intuito de identificar as possíveis fragilidades advindas do processo de gestão compartilhada, propor as devidas medidas 
corretivas e cooperar para a elaboração do Plano de Manejo da área, que deve ser elaborado no prazo de cinco anos a partir da data de sua criação (Art. 27, § $3^{\circ}$ da Lei 9.985/00).

Botkin \& Keller (2011) entendem que o monitoramento ambiental é o processo de coleta de informação regular em locais específicos para obter uma base de dados da qual se pode avaliar, citando, como exemplo, a coleta de amostras de água debaixo de um aterro para dar um alerta antecipado, caso haja algum problema de poluição. 0 monitoramento ambiental da unidade é de fundamental importância, para que as organizações e órgãos públicos possam antever o risco de acidentes, incêndios, queimadas, desmatamentos, caça e pesca ilegal e contaminação dos recursos hídricos passíveis de danos sobre os recursos ambientais e, assim, adotar tempestivamente medidas preventivas e eficazes no sentido de minimizar impactos negativos.

\section{RESULTADOS ESPERADOS}

A atual APA Barra do Piraí encontra-se fortemente impactada pela ocorrência de crimes ambientais diversos em seu interior e adjacências, vulnerável e indefesa diante da visível e concreta omissão do Poder Público Municipal em assumi-la integralmente e dotá-la de todos os meios e instrumentos indispensáveis e adequados ao seu manejo e controle. Com a devida implantação do Plano de Ação sugerido e a elaboração do respectivo Plano de Manejo, a APA Barra do Piraí receberá a proteção necessária para compatibilizar as atividades de visitação guiada com a proteção dos recursos ambientais existentes e que corroborá para que se torne sustentável. Vale grifar que a referida área protegida não consta do cadastro nacional de unidades de conservação do Ministério do Meio Ambiente, que conta com o apoio dos estados, municípios e ONGs. Com a realização dessas propostas, será possível amenizar e/ou eliminar as fragilidades detectadas e potencializar ações de incentivo que permitam à aproximação das pessoas ao meio ambiente natural, de forma harmônica e de ampla reciprocidade.

\section{CONSIDERAÇÕES FINAIS}

Após a implantação desses projetos sugeridos, esperam-se mudanças positivas e significativas em prol da APA, considerando-se a riqueza da diversidade ecológica existente e ainda desconhecida e seus valores associados, os recursos hídricos disponíveis, os solos, os ecossistemas e paisagens frágeis, buscando sempre a manutenção de sua integridade e funções ecológicas. Recomenda-se também a urgente recomposição das quinze nascentes, por meio de medidas de reflorestamento da mata ciliar dos córregos existentes que cortam a APA. Para auxiliar no processo de estabilização de diversas voçorocas existentes, será necessária a construção de canaletas de cristas de talude e degraus, conforme o relatório técnico produzido pelo Departamento de Recursos Minerais do Estado do Rio de Janeiro (Anexo). A inércia da Prefeitura Municipal de Barra do Piraí é evidente, pois, desde a edição da Lei Municipal no 1.190, de 01 de dezembro de 2006, que dispõe sobre a transformação do Parque Florestal em Área de Proteção Ambiental, passaram-se doze anos e, nesse lapso de tempo, não se observa nenhuma ação concreta e significativa de caráter público que sinalize a responsabilidade da gestão de tão importante e significativa área de interesse ambiental. 


\section{REFERÊNCIAS}

ANCHITE, J. L., Decreto Municipal n³0/2008. Regulamenta o Conselho Gestor da Área de Proteção Ambiental do Município de Barra do Piraí. Barra do Piraí/RJ, 2008.

ANTUNES, P. B. Áreas Protegidas e Propriedade Constitucional.. São Paulo: Editora Atlas, 2011. 178p.

ASSIS, J. C. Plano Básico de Sustentabilidade para São Sebastião do Alto. Conselho Regional de Engenharia, Arquitetura e Agronomia do Estado do Rio de Janeiro/CREA-RJ. Rio de Janeiro. 2010. 61p.

BOTKIN, D. B. \& KELLER, E. A. Ciência ambiental: terra, um planeta vivo. 7. ed. Rio de Janeiro: Editora LTC, 2011. 681p.

BRASIL. Constituição Federal de 05 de outubro de 1988. Brasília. Distrito Federal.

. Lei Federal n 9.795/99. Política Nacional de Educação Ambiental. 1999. Brasília. Distrito Federal. Lei Federal n 9.985/00. Sistema Nacional de Unidades de Conservação, 2000. Brasília, Distrito Federal.

CÂMARA, I. G. Plano de Ação para Mata Atlântica. UNESCO/Programa MAB - "O Homem e a Biosfera". São Paulo. 1996. 40p.

CASARA, H. Projeto de Lei $n^{\circ}$ 3.948. Nova legislação sobre animais nativos. Dispõe sobre a Política Nacional de Fauna e dá outras providências. O Congresso Nacional - Capítulo II Art. 6o Incisos XXI e XXII. 2004.

CHAVES, M. C. A importância da criação de Unidades de Conservação para a preservação da Biodiversidade: Estudo de caso da criação do Parque Natural Municipal do Açude da Concórdia - PaNaMAC - 2006, 36p. Monografia apresentada ao Programa de Pós-graduação em Gestão Ambiental do Centro Universitário de Volta Redonda (UniFOA).

COELHO, M. C. N.; CUNHA. L. H. \& MONTEIRO, M. A. Unidades de Conservação: populações, recursos e territórios. Abordagens da Geografia e da Ecologia Política. In: GUERRA, A. J. T. \& COELHO, M. C. N. (Organizadores) Unidades de Conservação: abordagens e características geográficas. Rio de Janeiro: Editora Bertrand Brasil, 2009.

COSTA, D.; SOUZA, T. C. O. Coordenadores. Plano de Ação da APA Municipal de Barra do Piraí. Associação Ecológica Vale do Paraíba. Projetos Demonstrativos da Mata Atlântica. Ministério do Meio Ambiente. 2008. 30p.

FAILLACE, S. T. Certificação Florestal do FSC (Forest Stewardship Council) Inclusão do debate social e ambiental no manejo florestal - Projeto Brasil Sustentável e Democrático: Fase - Rio de Janeiro - Série Cadernos Temáticos, n9. 2001. 68p.

FRANCA, N. Elaboração de Plano de Ação em Unidades de Conservação. Ibase. Rio de Janeiro. Edição Iracema Dantas. 2006. 20p. 
LOUREIRO, C. F. B. ; AZAZIEL, M.; FRANCA, N.; BRASILEIRO, R. F.; MUSSI, S. M.; LAFAILLE, T. M. S.; LEAL, W. O. Educação ambiental e Gestão participativa em Unidades de Conservação. 3. ed. revisada e atualizada. Rio de Janeiro IBAMA/NEA, Sultane M. Mussi. 2008. 60p.

MATAREZI, J. Despertando os sentidos da educação ambiental. Educ. Rev. Curitiba. n 27. 2006.

MERLIN, S.; RESENDE, D. Revista Científica do Instituto Ecológico. Revista Carbono Social - Palmas: Instituto Ecológico - vol. 2, nº 02, p 34-46 - trimestral - Abr./Mai./Jun., 2008.

Ministério do Meio Ambiente. Cadastro Nacional de Unidades de Conservação. Disponível em: http:// www.mma.gov.br/images/arquivo/80238/CNUC_FEV18\%20-\%20B_Cat.pdf. Acesso em 22 mar. 2018.

OLIVEIRA, M. S. A. C., Justificativa para indicação de que o Parque Florestal seja classificado como APA (Área de Proteção Ambiental). Ministério do Meio Ambiente. Câmara Municipal de Barra do Piraí \& Secretaria Municipal de Meio Ambiente e Agricultura do Município de Barra do Piraí. 2006. 6p.

SANTILLI, J. Socioambientalismo e novos direitos. São Paulo: Editora Peirópolis, 2005. 303p.

SILVA, E. L. Conselhos Gestores de Unidades de Conservação: Ferramenta de Gestão Ambiental \& Estímulo à Participação Cidadã. 3. ed. Revisada e Ampliada. Rio Grande do Sul: 2007. 36p.

SOUZA, T. C. O. Área de Proteção Ambiental Municipal de Barra do Piraí. Ministério do Meio Ambiente/ Secretaria Municipal de Meio Ambiente e Agricultura do Município de Barra do Piraí. 2008. 16p.

TORREZ, R. E. B.; PIMENTA, T. S. Relatório Técnico: Avaliação Ambiental das Nascentes do Parque Florestal Municipal de Barra do Piraí e das Áreas Sujeitas às Atividades Mineradoras no Município de Barra do Piraí. Departamento de Recursos Minerais. Rio de Janeiro. 2007. 46p. 